\title{
WORKPLACE STRESS AND EMPLOYEES' WELL-BEING: EVIDENCE FROM LONG TERM CARE IN THE CZECH REPUBLIC
}

\author{
Blanka Jirkovská1, Hana Janečková2 \\ ${ }^{1}$ MIAS School of Business, Czech Technical University in Prague, Prague, Czech Republic \\ ${ }^{2}$ Third Medical Faculty, Charles University, Prague, Czech Republic
}

\section{SUMMARY}

Objectives: The aim of this study was to verify the Effort-Reward Imbalance (ERI) model, which served as the basic concept of mapping workplace stress, on the sample of Czech professional caregivers. ERI model examines the relationship between the long-term subjectively perceived level of workers' effort and rewards and analyses the physical and psychosocial consequences of the (im)balance.

Methods: The verification of ERI model in combination with well-being (and its psychosocial consequences) was conducted on a sample of Czech professionals caring for older people in $2014(\mathrm{~N}=265)$. The survey included 12 facilities providing health and social care services for older people. Facilities were chosen through purposive sampling and snowball technique. The sample was divided into the following subgroups: professionals working in residential or field services and medical or social workers.

Results: Results showed that the majority (57\%) of professional caregivers in both residential and field services suffered from imbalance caused by higher effort and lower rewards. Subgroup of medical workers in long-term care institutions formed the most demanded group with the highest imbalance between work effort and rewards $(68 \%)$. This discrepancy was reflected in a reduction of their well-being. This effect was most evident by the medical workers in home care. Well-being within this group was more than five times lower compared to other groups with ERI imbalance. Also, a group of social workers in institutions came out as a high-risk group in this regard.

Discussion: The level of imbalance differed among the defined groups. The data obtained verified the known facts about the adverse work situation of professionals in long-term care in the contemporary Czech environment. The outputs correspond to foreign studies and confirm the validity of ERI model on the sample of Czech professionals in the long-term care.

Key words: aging, effort-reward imbalance model, effort and rewards of employees, workplace stress, well-being, long-term care, professional caregivers

Address for correspondence: B. Jirkovská, MIAS School of Business, Czech Technical University in Prague, Kolejní 2637/2A, 16000 Prague 6, Czech Republic. E-mail: blanka.jirkovska@email.cz

https://doi.org/10.21101/cejph.a5135

\section{INTRODUCTION}

The topic of population aging and the needs associated with long-term care (LTC) are increasingly discussed in the frame of global debates on public health in the twenty-first century (1). These themes are placed on the list of new social risks (2). Between the years 2010-2050 the number of people over eighty within the member countries of the OECD will be more than doubled, when the current $4 \%$ of those people will increase to nearly $10 \%$ (3). The necessity of planning processes and provision of LTC is evoked by these fundamental changes of demographic and social nature.

Among other things, the number of professional caregivers in the LTC sector (both social and health care staff) should be increased. Their amount will double globally by 2050 according to the OECD expectations and even triple in the Czech Republic (2). Although the longer stay of frail older people at their home seems to be preferable in terms of economic and psychological reasons, it cannot be provided in many cases. Therefore, it is necessary to offer appropriate institutional care to those older people who need it (4). At present, the Czech Republic is experiencing a shortage of quality long-term care services (especially for people suffering from dementia) and a shortage of qualified staff providing care.

This paper deals with selected aspects of the work situation of LTC professionals in the Czech Republic. The article aims to contribute to the debate on shortcomings of the LTC current state in the Czech Republic through the results of research that maps the work situation in selected LTC facilities and services in Prague and its surroundings.

\section{Theoretical Concepts}

There are two theoretical concepts, which served as a background for this study. The first one is the Siegrist's model of Effort-Reward Imbalance (ERI), which reflects the subjective perception of effort the employees put into their work, and rewards they receive for it. The perception of imbalance in these two components can bring health and psychosocial consequences 
(4). Research linked to ERI is a part of a wider scientific field that studies the influence of psychosocial factors on human health. The experience of individuals in their key social roles at work, family or community and its effects on health is analysed through specific theoretical and methodological tools, the ERI model being one of them (5-7).

The basic idea of the ERI model states that the worker puts effort into his activities as a part of the socially organized process of exchange, which balances that effort by adequate rewards. Rewards are distributed in the society with three transmission systems: money, recognition and self-development, along with job security and with maintaining of the employment status (sometimes called status control) (5). The ERI model has been used in many studies with different topical orientations from the beginning of its existence. The model originally followed the cardiovascular consequences of the long-term imbalance between high effort and low rewards experienced by employees (8). Since the end of the twentieth century, the use of the model spread to other areas.

The second theoretical concept, well-being, concerns the psychosocial area of human life and in our case it describes whether and to what extent employees in the long-term care sector feel well. Well-being is perceived in different ways in accordance with a focus on sociological, psychological, medical or economical perspectives. In social sciences, well-being is often mentioned in connection with the quality of life and lifestyle. The quality of life consists of two basic dimensions: subjective and objective. Subjective dimension is usually described as a composition of the psychological well-being, personal mastery, self-esteem and self-efficacy. Objective dimension is characterized by the health status, functional capacity of the organism and also by the socioeconomic status. The mentioned components are further divided into more specific categories (9).

\section{Research Goal and Main Research Questions}

To map the work situation in selected LTC services in Prague and surroundings the Siegrist's model of Effort-Reward Imbalance was used in combination with well-being concept as described by other authors in previous studies (5-7).

Based on the literature findings, we have designed our research questions to verify the validity of ERI model in combination with the concept of well-being among the sample of LTC staff from Prague and surroundings.

The first research question asked if there is a statistically significant relationship between results in ERI model and wellbeing indicators in our research sample of professional caregivers.

The second research question inquired which of the well-being dimensions (physical, social or psychological) contributes most significantly to the ERI model explanation.

The third research question asked whether there are significant differences in the level of ERI model imbalance between various subgroups of LTC workers.

\section{MATERIALS AND METHODS}

First, there was a qualitative preliminary research, in which we conducted six focus groups with twenty-nine employees in five LTC organizations.
The quantitative research was conducted on the population of the employees of institutional and field services in LTC for older people. 431 questionnaires were distributed in several waves from January to November 2014 . Return rate was $61.5 \%$ so the final research sample of respondents consisted of 265 LTC professionals. The sample description is summarized in Table 1 .

\section{Data Collection}

We have not tried to obtain a representative sample for the Czech Republic, therefore, we chose unrepresentative selection of LTC facilities and services, namely a combination of purposive sampling and snowball sampling method. A similar process of sample selection was used in several foreign studies conducted in medical and social environment $(5,7)$. The distribution of questionnaires (in paper or electronic form) followed the communication and agreement with management of the participating organizations.

Table 1. Basic characteristics of the sample - number of returned questionnaires $(N=265)$

\begin{tabular}{|c|c|c|c|}
\hline \multicolumn{2}{|c|}{ Basic characteristics of sample } & $\mathrm{n}$ & $\%$ \\
\hline \multirow{2}{*}{ Sex } & Male & 22 & 8 \\
\hline & Female & 241 & 92 \\
\hline \multirow{6}{*}{ Age } & Less than 25 & 20 & 8 \\
\hline & $26-35$ & 40 & 15 \\
\hline & $36-45$ & 77 & 30 \\
\hline & $46-55$ & 75 & 29 \\
\hline & $56-65$ & 45 & 17 \\
\hline & 65 and more & 1 & 0.4 \\
\hline \multirow{6}{*}{ Education } & Basic school & 12 & 5 \\
\hline & High school without SAT & 55 & 21 \\
\hline & High school with SAT & 125 & 48 \\
\hline & Higher vocational school & 34 & 13 \\
\hline & University - bachelor's degree & 21 & 8 \\
\hline & University - master's degree & 14 & 5 \\
\hline \multirow{5}{*}{$\begin{array}{l}\text { Length } \\
\text { of work } \\
\text { in LTC }\end{array}$} & Less than 1 year & 20 & 8 \\
\hline & $1-3$ years & 50 & 19 \\
\hline & $4-10$ years & 91 & 35 \\
\hline & $11-15$ years & 50 & 19 \\
\hline & More than 15 years & 50 & 19 \\
\hline \multirow{5}{*}{$\begin{array}{l}\text { Length } \\
\text { of work } \\
\text { in facility }\end{array}$} & Lless than 1 year & 40 & 15 \\
\hline & $1-3$ years & 59 & 23 \\
\hline & $4-10$ years & 95 & 37 \\
\hline & $11-15$ years & 38 & 15 \\
\hline & More than 15 years & 28 & 11 \\
\hline \multirow{2}{*}{$\begin{array}{l}\text { Work } \\
\text { position }\end{array}$} & Superior & 80 & 31 \\
\hline & Subordinate & 181 & 69 \\
\hline
\end{tabular}

Source: own data. The total number of answers does not have to correspond with the number of answers in particular characteristics because some respondents did notanswer. LTC - long-term care; SAT - Scholastic Aptitude Test 


\section{Sample of Respondents}

The sample of respondents consisted of employees of twelve LTC organizations. Eleven of them were located in Prague, one in its surroundings. As for the types of services, they were the following: two in-patient departments providing LTC, three agencies providing both home care and home help, two home care agencies providing just health care, three residential homes for older people (out of them one was specialized in dementia care), and two providers of the personal assistance at home. Table 2 shows the distribution of the job positions in the sample.

Table 2. Distribution of research sample by work position $(N=265)$

\begin{tabular}{|l|c|c|}
\hline Work position & $\mathbf{n}$ & $\%$ \\
\hline Registered nurse & 90 & 34.2 \\
\hline Medical assistant/aid & 33 & 12.5 \\
\hline Chief/head nurse & 10 & 3.8 \\
\hline Social worker & 25 & 9.5 \\
\hline Formal caregiver in direct care service & 77 & 29.3 \\
\hline Activation worker & 16 & 6.1 \\
\hline Personal assistant & 8 & 3.0 \\
\hline Cleaning staff & 6 & 2.3 \\
\hline
\end{tabular}

Source: own data

For our purposes, we divided the sample into the following four subgroups: Group 1 - medical workers in LTC institutions $(\mathrm{n}=96)$; Group 2 - medical workers in LTC field services $(\mathrm{n}=$ 54); Group 3 - social workers in LTC institutions $(n=56)$; Group 4 - social workers in LTC field services $(n=59)$. Medical workers included registered nurses, head nurses and auxiliary health workers. Social workers included social workers, formal caregivers in direct care, activation workers, personal assistants, and cleaning staff in social institutions.

We assumed that this division of our respondents might show a difference in the perception of workload and its impact on the well-being of individuals. Workers in medical area in comparison with workers in social area perform different types of activities, they have different competencies and responsibilities. Work of respondents in the institutions compared to those from home care is dissimilar in many respects.

\section{Construction of Measures and Indicators}

In our survey, we used a shortened version of the ERI questionnaire (labelled ERI-S) (15). The authors argue that this shorter version of the original questionnaire is easier to use especially in large epidemiological studies. For well-being three dimensions were distinguished: physical, psychological and social. Each of them was represented by indicators that were used in similar studies (16). They extended from zero to six. We subsequently performed dichotomizing for the purpose of logistic regression. We arbitrarily set the boundary between good and bad well-being; good well-being was represented by values $0,1,2$ and bad wellbeing was represented by values $3,4,5,6$.

To answer the question which of the dimensions of well-being contributes significantly to the explanation of the ERI model we used the Nagelkerke's coefficient of determination which explains the proportion of explained variance of dependent variable by independent variable(s) (10). This coefficient served as a criterion for an explanation of ERI model in terms of the dependent variable. In Table 4 , the coefficient is referred to as $* \mathrm{R}^{2}$. Our data were analysed using IBM SPSS Statistics, version 24.

\section{RESULTS}

The analysis has brought the evidence that confirmed the validity of the first research question about the relationship between the ERI model and the concept of well-being by a sample of the caring professionals in the Czech Republic. Namely those respondents who subjectively perceived imbalance between higher work effort and lower rewards in the LTC had lower levels of well-being.

Table 3 provides a more detailed analysis of the relationship between ERI model imbalance and well-being. The first column of Table 3 indicates the division of respondents into sub-groups as mentioned before. The second column indicates the number of respondents in each group. The third column contains the odds ratio of worse well-being among respondents with high imbalance according to the ERI model (high effort, low rewards) in comparison with those who do not perceive this imbalance. In summary, there is about three to five times higher chance of a worse well-being among respondents with high imbalance according to the ERI model. After looking at the total sample of respondents, it can be seen that there is almost three times (2.98) higher chance of lower well-being among respondents with high effort-low rewards imbalance in comparison with those who do not perceive the imbalance. Within four defined subgroups, a group of medical workers in home care has the highest risk (more than five times higher-5.22) of worse well-being when suffering from imbalance according to the ERI model compared to those who do not perceive this imbalance. Also, the group of the social workers in institutions who feel a great work effort, which is not sufficiently compensated by the rewards, is almost four and a half times more exposed to the worse well-being. Only the group of social workers in the home care did not show any statistically significant relationship between ERI and well-being.

The bottom half of Table 3 is divided into all medical workers and all social workers on one hand and into all workers in institutions and all workers in home care on the other hand. The validity of the first hypothesis was confirmed under this division as well. Moreover, the differences between the responses of all medical and all social workers are statistically significant. Also, the responses of all workers in institutions compared to all workers in the home care are statistically significant. This means that medical workers reported significantly lower well-being due to high ERI than social workers. Similarly, workers in long-term care institutions showed significantly lower well-being due to ERI compared to workers in home care.

As can be seen in Table 3, all odds ratios (OR) are statistically significant with the exception of social workers in home care. The higher the OR the higher the chance to worse well-being due to the high ERI. The difference between OR of medical and social workers and the difference between OR of institutional and home care workers are also statistically significant. 
Table 3. Relationship between ERI model and well-being $(N=265)$

\begin{tabular}{|l|c|c|}
\hline Groups & $\mathbf{n}$ & $\begin{array}{c}\text { Logreg ERI-WB } \\
\text { OR (SD) }\end{array}$ \\
\hline Total & 265 & $2.98(0.22)$ \\
\hline Medical workers in institutions & 96 & $3.51(0.35)$ \\
\hline Medical workers in home care & 54 & $\mathbf{5 . 2 2 ( 0 . 7 0 )}$ \\
\hline Social workers in institutions & 56 & $\mathbf{4 . 4 3 ( 0 . 6 2 )}$ \\
\hline Social workers in home care & 59 & $1.78(0.44)$ ns \\
\hline All medical workers & 150 & $3.22(0.29)$ \\
\hline All social workers & 115 & $2.50(0.36)$ \\
\hline All workers in institutions & 152 & $3.87(0.30)$ \\
\hline All workers in home care & 113 & $2.56(0.38)$ \\
\hline
\end{tabular}

ERI - Effort-Reward Imbalance; WB - well-being; OR - odds ratio; SD - standard deviation; ns - non-significant.

Numbers in bold indicate statistically significant values.

To answer the second research question on the contribution of three well-being dimensions (physical, psychological and social) to the ERI model explanation, we have to look at the level of determination coefficient for the individual dimensions of well-being. Table 4 shows that the psychological dimension (measured by the risk of burnout, work motivation and job satisfaction) contributes the most to explain the model, almost 20\%. More detailed split on subgroups shows that medical workers in home care who suffer from imbalance in the ERI model have almost eight times lower psychological well-being. Also, the workers from the medical sub-group have generally four and a half times higher risk of poor psychological well-being when feeling long-term imbalance according to the ERI model.

The physical dimension (measured by the subjective assessment of health status during the last 12 months) is a second strongest dimension explaining the ERI model of almost $10 \%$. The chance of poorer health is more than four times stronger in the medical staff in home care who feel imbalance according to the
ERI model in comparison with medical staff without this imbalance. The group of social workers in LTC institutions with higher work effort and lower rewards have almost four times higher risk of bad health status in comparison with those who feel balance.

The social dimension of well-being (measured through questions on the quality of relationships among workers and with supervisors) has no statistically significant effect on the ERI model. In other words, workplace relations are not affected by the long-term imbalance between work effort and rewards. This result is consistent with the previous findings we have obtained in the preliminary qualitative research. Participants repeatedly stated that good relationships with co-workers and with direct supervisors were a crucial motivating factor for them and good relationships at workplace form an important prerequisite for job satisfaction. If these relationships were not good and the communication between management and employees stagnates, it would have been reflected in the overall feeling of discomfort.

The third research question, asking how significantly levels of ERI differ between the sub-groups, was answered through calculating the average values of adjusted ERI coefficient for individual groups. Then a category called "ERI risk" was constructed. This category determines the percentage of the respondents in each sub-group who have a non-equilibrium state in the ERI model (higher effort and lower rewards), compared to those who have either a sense of balance, or a sense of more rewards than effort.

Data showed in Table 5 provide answer to the third research question. When assessing the differences between ERI averages in four defined sub-groups, we can see that the medical workers in institutions have the highest ERI imbalance. This value is significantly different from the values of the remaining three groups, whose means are similar. Results showed that all medical workers have significantly higher imbalance according to the ERI model than all social workers and all workers in institutions have a significantly higher ERI imbalance than all home care workers.

The right column in Table 5 shows that the feeling of the longterm imbalance between higher work effort and lower rewards occurs in $46-68 \%$ of respondents. The highest proportion of respondents suffering from imbalance between their effort and

Table 4. Relationship between ERI model and dimensions of well-being $(N=265)$

\begin{tabular}{|l|c|c|c|c|}
\hline Groups & $\mathbf{n}$ & $\begin{array}{c}\text { Logreg ERI-WB } \\
\text { psychological } \\
\text { OR (SD) }\end{array}$ & $\begin{array}{c}\text { Logreg ERI-WB physical } \\
\text { OR (SD) }\end{array}$ & $\begin{array}{c}\text { Logreg ERI-WB social } \\
\text { OR (SD) }\end{array}$ \\
\hline Total & 265 & $\begin{array}{c}3.20(0.23) \\
\mathrm{R}^{2}=19.40 \%\end{array}$ & $\begin{array}{c}1.87(0.17) \\
\mathrm{R}^{2}=9.70 \%\end{array}$ & $\begin{array}{c}1.19(0.14) \mathrm{ns} \\
\mathrm{R}^{2}=1.00 \%\end{array}$ \\
\hline Medical workers in institutions & 96 & $4.29(0.40)$ & $1.86(0.23)$ & $1.18(0.42) \mathrm{ns}$ \\
\hline Medical workers in home care & 54 & $7.84(0.76)$ & $4.30(0.66)$ & $1.36(0.31) \mathrm{ns}$ \\
\hline Social workers in institutions & 56 & $2.77(0.53)$ & $3.81(0.57)$ & $1.64(0.58) \mathrm{ns}$ \\
\hline Social workers in home care & 59 & $1.71(0.44) \mathrm{ns}$ & $1.42(0.38) \mathrm{ns}$ & $1.12(0.45) \mathrm{ns}$ \\
\hline All medical workers & 150 & $4.53(0.34)$ & $1.85(0.20)$ & $1.20(0.16) \mathrm{ns}$ \\
\hline All social workers & 115 & $2.00(0.33)$ & $2.10(0.34)$ & $1.27(0.34) \mathrm{ns}$ \\
\hline All workers in institutions & 152 & $3.93(0.31)$ & $2.00(0.21)$ & $1.18(0.18) \mathrm{ns}$ \\
\hline All workers in home care & 113 & $2.95(0.41)$ & $2.13(0.35)$ & $1.27(0.25) \mathrm{ns}$ \\
\hline
\end{tabular}

ERI - Effort-Reward Imbalance; WB - well-being; OR - odds ratio; SD - standard deviation; $\mathrm{R}^{2}$ - Nagelkerke's coefficient of determination; ns - non-significant. Numbers in bold indicate statistically significant values. 
Table 5. Level of ERI for each group of the research group $(N=265)$

\begin{tabular}{|l|c|c|c|}
\hline Groups & $\mathbf{n}$ & $\begin{array}{c}\text { Mean } \\
\text { adjusted ERI } \\
\text { (SD) }\end{array}$ & $\begin{array}{c}\text { ERI risk } \\
\mathbf{n}(\%)\end{array}$ \\
\hline Total & 265 & $1.34(1.15)$ & $150(57)$ \\
\hline Medical workers in institutions & 96 & $1.67(1.48)$ & $65(68)$ \\
\hline Medical workers in home care & 54 & $1.12(1.04)$ & $25(46)$ \\
\hline Social workers in institutions & 56 & $1.14(0.68)$ & $29(52)$ \\
\hline Social workers in home care & 59 & $1.17(0.85)$ & $31(53)$ \\
\hline All medical workers & 150 & $1.47(1.36)$ & $90(60)$ \\
\hline All social workers & 115 & $1.16(0.76)$ & $60(52)$ \\
\hline All workers in institutions & 152 & $1.48(1.27)$ & $94(62)$ \\
\hline All workers in home care & 113 & $1.14(0.94)$ & $54(49)$ \\
\hline
\end{tabular}

ERI - Effort-Reward Imbalance; SD - standard deviation

The higher the adjusted ERI mean (third column), the higher the ERI imbalance. Numbers in bold indicate statistically significant values

rewards can be found in a group of medical workers in institutions $(68 \%)$. This result proves the known problem of poor working conditions in LTC hospitals in the Czech Republic. They are seen as relatively low-cost way of placing frail older people with medical, financial, family or social problems to an institution. Many people placed in these LTC hospitals could stay at their households (with the help of home care services) or in a residential home. Staff in these LTC hospitals is overloaded with work, has low salary and unsatisfactory work conditions. All these factors can cause high work stress and dissatisfaction of the personnel.

\section{DISCUSSION}

Our research proved the validity of the ERI model in our conditions. Its results correspond with the previous research combining ERI model and well-being concept, which had brought the evidence regarding the impact of the ERI imbalance on various dimensions of person's well-being.

In 2005 Van Vegchel et al. (8) published a review monitoring 45 empirical studies of the ERI model conducted in different countries between 1986 to 2003. Most of these studies confirmed that the ERI model imbalance increases the risk of psychosomatic symptoms, ranging from 1 to 19 times higher occurrence of psychosomatic symptoms in comparison with those individuals whose effort and rewards are balanced.

Bakker et al. (7) conducted research among 204 nurses in Germany. They tested the hypothesis that high imbalance between effort (external labour demand) and low external rewards are associated with burnout syndrome. Analysis confirmed the hypothesis that nurses who showed imbalance in terms of longterm high job demands and low rewards scored higher in two of the three key dimensions of burnout (emotional exhaustion and depersonalization) compared to those nurses who have not felt the ERI model imbalance.

The team of Dutch researchers led by De Jonge (11) published another study combining the ERI model and well-being. They collected data from a large representative sample of 11,636 Dutch employees. Well-being was composed as an aggregate comprising the following components: emotional exhaustion, psychosomatic ailments, physical health symptoms, and job satisfaction. The hypothesis that imbalance between long-term high effort and low work rewards leads to deterioration of well-being was confirmed.

In their earlier work, Van Vegchel et al. (5) compared the effect of ERI and well-being at 167 ancillary health workers. Well-being acted again as a variable composed of several indicators: psychosomatic health problems, physical health symptoms, exhaustion and job satisfaction. The results confirmed the hypothesis that long-term ERI imbalance worsened well-being.

In 2006, author of the ERI model Johannes Siegrist and his colleagues (12) focused on the relationship between the quality of working life, well-being and the intention of older workers to leave for early retirement. The results showed that both low quality of working life (ERI model imbalance) and low level of well-being have an independent effect on the intention to leave for early retirement.

In their recent study a Finnish-German research team also combined the ERI model and well-being (6). Feldt et al. examined how long-term ERI model imbalance affected well-being of employees and their psychological recovery. Well-being contained two key indicators: the risk of burnout and work engagement. The study was based on three consecutive surveys conducted in the years 2006, 2008 and 2010. The research sample consisted of 298 Finnish managers. Results showed that managers characterized by the high effort and lack of rewards had higher affinity with burnout and also lower ability of psychological recovery. A linkage between ERI model imbalance and work commitment was not proved. The authors concluded that the ERI model could explain indicators related to stress (burnout), rather than indicators related to motivation (work engagement).

\section{CONCLUSION}

To sum up, the successful verification of the ERI model and its influence on well-being was done on the sample of LTC professional caregivers in Prague and surroundings. Our research proved that LTC workers who felt imbalance between high job effort and low rewards in longer perspective showed reduction in their well-being.

The study has several methodological limits. The sample selection was not representative, so the results could not be generalized for the entire Czech population. Also, duration of data collection in 2014 has to be taken into account. Relatively long-time span was caused by the need to fetch sufficient number of data for subsequent statistical analysis.

Despite the limits, we can say that the data obtained through our research contributed to the description and deeper recognition of the work situation in selected LTC facilities and services in Prague and its surroundings. Our results illustrate the wellknown facts about the existence of adverse work conditions for LTC professionals in the Czech environment (13). Our findings correspond with foreign studies, which also mention the poor quality of working conditions of people caring for the older adults (3-5). Therefore, the greater emphasis should be put on the needs of LTC professionals within the framework of national debates on the impact of aging on population in the Czech Republic. The professional carers play an important role in care for frail old 
people besides the family members and other informal carers (14). Improvement of the working conditions of professional carers and greater societal appreciation of their work seems to be an important prerequisite of successful ageing in our society.

\section{Acknowledgements}

The authors wish to acknowledge the managements and the respondents from the LTC organizations who participated in the study.

\section{Conflict of Interests}

None declared

\section{REFERENCES}

1. Krajic K, Schmidt C, Christ R. Health promotion in the long term care in Austria: the status quo analysis. Soziale Sicherheit. 2010;3:142-8. (In German.)

2. Průša L. Model of effective financing and provision of the long term care. Prague: RILSA; 2011. (In Czech)

3. Colombo F, Mercier J. Help wanted! Balancing fair protection and financial sustainability in long-term care. Eurohealth. 2011;17(2-3):3-6.

4. Siegrist J, Rödel A. Workloads in the long-term care: with emphasis on problem of new start. Düsseldorf: Institute for Medical Sociology of Heinrich Heine-University Düsseldorf; 2005. (In German.)

5. Van Vegchel N, Jonge J, Meijer T, Hamers J. Different effort constructs and effort-reward imbalance: effects on employee well-being in ancillary health care workers. J Adv Nurs. 2001;34(1):128-36.

6. Feldt T, Huhtala M, Kinnunen U, Hyvönen K, Mäkikangas A, Sonnentag S. Long-term patterns of effort-reward imbalance and over-commitment: Investigating occupational well-being and recovery experiences as outcomes. Work Stress. 2013;27(1):64-87.
7. Bakker A, Killmer C, Siegrist J, Schaufeli W. Effort-reward imbalance and burnout among nurses. J Adv Nurs. 2000;31(4):884-91.

8. Van Vegchel N, De Jonge J, Bosma H, Schaufeli W. Reviewing the effort-reward imbalance model: drawing up the balance of 45 empirical studies. Soc Sci Med. 2005;60(5):1117-31.

9. Šolcová I, Kebza V. Quality of life in psychology: well-being, its determinants and predictors. In: Hnilicova H, editor. Quality of life; 2004 Oct 25; Třeboň. Kostelec nad Černými lesy: Institute of health policy and economy; 2004. p. 21-32. (In Czech.)

10. Reháková B. Introducing logistic regression. Soc Cas. 2000;36(4):475-92. (In Czech.)

11. De Jonge J, Bosma H, Peter R, Siegrist J. Job strain, effort-reward imbalance and employee well-being: a large-scale cross-sectional study. Soc Sci Med. 2000;50(9):1317-27.

12. Siegrist J, Wahrendorf M, Von dem Knesebeck O, Jürges H, Börsch-Supan A. Quality of work, well-being, and intended early retirement of older employees-baseline results from the SHARE Study. Eur J Public Health. 2006;17(1):62-8.

13. Janečková $H$, Hnilicová $H$. Introduction to public health. Prague: Portál; 2009. (In Czech.)

14. Křížová E, Janečková H, Běláček J. Family carers'perspectives on integrated community care in the Czech Republic. Cent Eur J Public Health. 2016;24(4):289-96.

15. Siegrist J, Montano D. ERI - Questionnaires - Users Guide [Internet]. The Institute of Medical Sociology in Düsseldorf; 2012 [cited 2019 Mar 5]. Available from: http://www.uniklinik-duesseldorf.de/.

16. Mansor N, Wai C, Mohamed A, Shah I. The Relationship between management style and employees' well-being: a case of non-managerial staffs. Procedia Soc Behav Sci. 2012;40:521-9.

Received May 10, 2017 Accepted in revised March 5, 2019 